\title{
Tratamento com diálise peritoneal: a prática do autocuidado no contexto familiar
}

\author{
Peritoneal dialysis treatment: self-care practice in the family context \\ Tratamiento con diálisis peritoneal: la práctica del autocuidado en el contexto familiar
}

\author{
Joyce Martins Arimatea Branco Tavares'; Marcia Tereza Luz Lisboa ${ }^{\text {Il }}$
}

\begin{abstract}
RESUMO: Os objetivos do estudo foram identificar as dificuldades enfrentadas pelos clientes ao realizar a diálise peritoneal ambulatorial contínua (DPAC) no domicílio e analisar as soluções por eles adotadas para lidar com elas. Recorte de dissertação aprovada em 2010, sendo um estudo descritivo, qualitativo, que utilizou o método da Pesquisa Convergente-Assistencial, cujo cenário foi um hospital estadual do Rio de Janeiro. Realizaram-se três grupos de encontros com nove sujeitos. A técnica da entrevista semiestruturada originou temas que resultaram na categoria convivência com o tratamento - pontos dificultadores na realização da DPAC no domicílio. Os participantes afirmaram que dificuldades do tratamento podem ser superadas mediante adaptação individual com auxílio da equipe de enfermagem, de redes de apoio e de familiares. Demonstrou-se a necessidade de que o modelo pedagógico utilizado para o processo educativo dos clientes seja repensado, intermediando os saberes científicos com os saberes populares.

Palavras-Chave: Enfermagem; autocuidado; diálise peritoneal; educação em saúde.
\end{abstract}

\begin{abstract}
The study objectives were to identify the difficulties faced by clients in performing continuous ambulatory peritoneal dialysis (CAPD) at home, and to analyze the solutions they encountered. Drawn from a dissertation approved in 2010, article reports a descriptive, qualitative study using the Convergent-Care Research method. With a state hospital in Rio de Janeiro as scenario, three groups of meetings were held with nine subjects. The semi-structured interview technique yielded themes that resulted in the category coexisting with the treatment - difficult points in carrying out CAPD at home. The participants noted that difficulties in the treatment can be overcome by individual adaptation with the help of nursing staff, support networks and family. It was demonstrated that the teaching model used for client education needs to be rethought so as to mediate between scientific knowledge and popular knowledge.

Keywords: Nursing; self-care; peritoneal dialysis; health education.

RESUMEN: El objetivo del estudio consistió en identificar las dificultades enfrentadas por los clientes al realizar diálisis peritoneal continua ambulatoria (DPCA) en casa y analizar las soluciones adoptadas para hacerles frente. Parte de disertación aprobada en 2010, consistiendo en un estudio descriptivo y cualitativo que utiliza el método de Investigación Convergente Asistencial. En el escenario, un hospital del estado de Río de Janeiro, tuvieron lugar tres grupos de encuentros con nueve individuos. La técnica de entrevista semiestructurada originó temas resultaron en la categoría Convivencia con el tratamiento - puntos que dificultan la realización de la DPCA en casa. Los participantes señalaron que las dificultades del tratamiento se pueden superar mediante la adaptación individual con ayuda del personal de enfermería, de redes de apoyo y de la familia. Se ha demostrado la necesidad de que el modelo pedagógico utilizado para el proceso educacional de los clientes sea repensado, intermediando el conocimiento científico con los saberes populares.

Palabras Clave: Enfermería; autocuidado; diálisis peritoneal; educación en salud.
\end{abstract}

\section{INTRODUÇÃO}

A doença renal crônica (DRC) vem se configurando em objeto de extrema importância e preocupação, no campo da saúde pública, devido à sua elevada morbidade e mortalidade ${ }^{1}$. Definida pela perda progressiva e irreversível dos néfrons funcionais, é classificada em cinco estágios que se relacionam com a taxa de filtração glomerular (TFG) e, consequentemente, com o grau de insuficiência. Na categoria mais avançada, o estágio cinco, intitulado insuficiência renal crônica (IRC) em estágio terminal, os rins perdem o controle total da homeostasia do organismo devido à grande redução dos néfrons, e o cliente começa a apresentar sintomas urêmicos e a necessitar de tratamento dialítico ${ }^{2}$.

Este artigo é um recorte de dissertação de mestrado, cujos objetivos foram identificar as dificuldades enfrentadas pelos clientes ao realizar a diálise peritoneal ambulatorial contínua (DPAC) no domicílio e analisar as soluções por eles adotadas para lidar com elas.

IDoutora em Enfermagem pela Escola de Enfermagem Anna Nery. Universidade Federal do Rio de Janeiro. Rio de Janeiro, Brasil. E-mail: joyarimatea@yahoo.com.br. IIProfessora Associada do Departamento de Enfermagem Fundamental da Escola de Enfermagem Anna Nery. Universidade Federal do Rio de Janeiro. Rio de Janeiro, Brasil. E-mail: marcialuzlisboa@gmail.com. 
A DPAC é um procedimento que consiste na infusão, retenção e drenagem para o interior do abdome, de uma solução balanceada e aquecida à temperatura próxima à do corpo. Nesse procedimento, o peritônio, uma membrana fina de revestimento de órgãos abdominais e da parede abdominal, é utilizado como membrana de troca por possuir muitos vasos capilares e linfáticos.

Os clientes em tratamento com a DPAC são selecionados e capacitados pela equipe de enfermagem para efetuar as trocas das bolsas em seus domić́lios. Essa seleção inclui a avaliação dos aspectos fisiopatológicos, sociais e emocionais, que deverão ser analisados, criteriosamente, a fim de que a entrada no programa de DPAC ocorra de forma efetiva.

Nessa perspectiva, o suporte informativo, que é oferecido ao cliente e à família, pode contribuir para a manutenção de sua saúde física e psicológica, na medida em que os ajuda a encontrar coerência para a própria vida, significado para o papel que desempenham e melhoria na forma de compreender o presente e esperar pelo futuro ${ }^{3}$.

\section{REFERENCIAL TEÓRICO}

Reportou-se aos pressupostos da Teoria do Autocuidado de Dorothea Orem ${ }^{4}$, juntamente com os conceitos de Paulo Freire ${ }^{5}$ sobre o processo de autonomia a ser aplicado na atividade educativa do cliente em DPAC.

Com relação à teoria, evidencia-se a existência de desejo e capacidade de executar o autocuidado ou o cuidado a membros dependentes da família. O primeiro é a parte da vida necessária à saúde, ao desenvolvimento e bem-estar. Educação e cultura influenciam os indivíduos em suas ações de autocuidado, aprendido pela interação e comunicação. Incluem-se aí condutas deliberadas e sistemáticas no sentido de satisfazer as exigências de saúde identificadas, próprias ou de outros. Essa teoria pressupõe que o cliente seja uma pessoa ativa no processo de decisão sobre a identificação das necessidades, natureza e ações a serem desenvolvidas no cuidado à saúde ${ }^{4}$.

A atividade de autocuidado é o poder, a competência ou o potencial da pessoa para engajar-se no próprio cuidado. É uma característica humana que se desenvolve no cotidiano através de um processo espontâneo de aprendizagem. Essa capacidade deve acompanhar o ciclo vital, iniciando-se na infância, atingindo seu ápice na fase adulta e declinando com a idade avançada, estando condicionada a fatores como idade, estado de desenvolvimento, experiência de vida, orientação sociocultural, saúde e recursos disponíveis ${ }^{4}$.

Tendo em vista o exposto, o respeito à autonomia e à dignidade de cada um é um imperativo ético, e não um favor que se pode ou não conceder aos outros ${ }^{5}$. Assim, é preciso respeitar a autonomia e a identidade do cliente com IRC, o que exige do profissional uma prática coerente com este saber.

Toda ação educativa que vise à autonomia dos indivíduos pressupõe o diálogo, que só será possível em uma relação horizontal, em que ambos os envolvidos se expressem como sujeitos, o que significa dizer que pessoas, situadas socioculturalmente em um determinado tempo e espaço, possam manifestar suas necessidades e desejos e, ainda, demonstrar sua capacidade de pensar, questionar e criticar, contribuindo para a solidificação desse processo de autonomia que está sendo construído dentro da realidade vivenciada e envolvendo a questão da participação familiar nesse contexto 5 .

A mudança de consciência, o respeito à autonomia e aos saberes dos clientes e o diálogo são indispensáveis no processo educativo. A pedagogia utilizada para educação é a ação que pode e deve ser muito mais que um processo de treinamento ou domesticação, e sim um processo que nasce da observação, da reflexão e culmina na ação transformadora. Uma educação que procura desenvolver a tomada de consciência e a atitude crítica, graças à qual o homem escolhe e decide, liberta-o, em lugar de submetê-lo, de domesticá-lo e de adaptá-lo 5 .

Nesse contexto, também se inserem as relações familiares, pois ocupam lugar de destaque na maneira como a maioria dos seres humanos enxerga e vivencia o mundo, tendo interferência no processo de autonomia. Falar de família é evocar um conjunto de valores que dota os indivíduos de uma identidade, e a vida, de um sentido 5 .

Cabe à enfermagem, portanto, entender a ligação entre a dinâmica familiar e o processo saúde-doença, o que exigirá conhecer a família, observar como se comporta frente às novas situações e procurar solucionar seus problemas, passando a entendê-la como um sistema com seu funcionamento, valores, práticas, rituais, forças e papéis específicos ${ }^{3}$.

\section{Metodologia}

Estudo descritivo, com abordagem qualitativa, tendo como método a Pesquisa Convergente-Assistencial $^{6}$ (PCA) que prevê as seguintes fases:

Fase da concepção - Relacionada com a origem da pesquisa, explicitando onde o desenvolvimento do estudo ocorreu, tendo em vista a experiência profissional na área de nefrologia, nesse caso, no serviço de DPAC, oportunizando a detecção da problemática em foco e a pesquisa dos referenciais teóricos disponíveis a respeito.

Fase da instrumentação/decisões metodológicas - O estudo foi concluído em 2010 e o cenário foi um hospital universitário da rede estadual, localizado no Rio 
de Janeiro, que conta com um serviço de nefrologia subdividido em DPAC, hemodiálise e transplante renal. Os clientes selecionados como sujeitos da pesquisa foram aqueles que tinham consultas de enfermagem e médica agendadas para o mesmo dia, aproveitando-se a oportunidade para explicar-lhes o projeto. Como critério de inclusão, decidiu-se pelos que estivessem desenvolvendo tratamento com a DPAC de forma independente, ou seja, sozinhos, sem a ajuda de um profissional do setor ou de familiar habilitado, mas que tivessem participado do processo educativo para a realização correta do procedimento.

Dos 21 clientes cadastrados no programa, foram incluídos nove que realizavam o tratamento há pelo menos três meses, tanto de forma manual, com quatro trocas de soluções diárias entre os períodos da manhã, tarde e noite, como de forma automatizada, com a utilização de cicladoras, máquinas específicas para o tratamento da DPAC, cabendo-lhes a responsabilidade de realizar esse método de diálise uma vez ao dia, no período noturno.

Nesse momento, identificou-se uma limitação do estudo, pois considerando os devidos critérios de inclusão, desses 21 clientes, apenas nove aceitaram participar da pesquisa e demostraram necessidade de rever suas práticas de autocuidado, desvelando as reais fragilidades do tratamento.

Para preservar o anonimato dos sujeitos, eles foram designados por nomes de flores. No primeiro momento da pesquisa, foi aplicado um roteiro de identificação para caracterizá-los; no segundo, houve a entrevista individual, gravada com autorização prévia dos sujeitos, e, posteriormente, transcrita na íntegra. Finalmente, no terceiro momento, formaram-se os grupos de convergência no cenário do estudo, ensejando a realização de três encontros com os sujeitos, sendo os temas de cada um definidos pelos próprios. Cada encontro durou entre $01: 15 \mathrm{~h}$ e $01: 45 \mathrm{~h}$, sendo também gravados em fitas magnéticas e, posteriormente, transcritos na íntegra.

Fase de perscrutação - Na captação dos sujeitos, foi entregue a cada um, para ciência e assinatura, o Termo de Consentimento Livre e Esclarecido (TCLE), em duas vias, sendo uma para as pesquisadoras e outra para o cliente, documento este com informações detalhadas sobre a pesquisa, de acordo com as normas de Bioética previstas na Resolução no 466/2012 do Conselho Nacional de Saúde (CNS).

Fase de análise e interpretação dos resultados - Os dados foram analisados de acordo com as etapas propostas pela PCA. Na fase de interpretação, encontra-se o processo de síntese, que permitiu examinar subjetivamente as associações e variações das informações; o processo de teorização desenvolveu um esquema teórico, a partir das relações reconhecidas durante o processo de síntese, quando se definiu detalhadamente a relação entre temas e conceitos; e, para finalizar, o processo de transferência, em que ocorreu a significação de determinados achados, contextualizando-os em situações similares, sem entendê-los como generalizações ${ }^{6}$.

$\mathrm{Na}$ fase inicial de apreensão, foi verificado, separadamente, todo o material produzido nas entrevistas individuais e nos grupos de convergência, para que não fossem gerados falsos resultados, pois, em uma dada situação, os sujeitos envolvidos na pesquisa responderam às questões, individualmente, e, em outra, houve a oportunidade de discutirem suas opiniões em conjunto.

material gerado nas entrevistas individuais e nas discussões dos grupos de convergência foi submetido à técnica de análise de conteúdo, visando manter a coerência no tratamento dos dados produzidos $^{7}$. Essa técnica permitiu identificar similaridades e divergências referentes a ambas as instâncias, embora circulassem em torno das mesmas temáticas. Dessa forma, constatou-se que os conteúdos provenientes das entrevistas individuais e dos grupos de convergência poderiam ser tratados em conjunto, por independerem de qualquer outra variável que determinasse mudanças entre elas ${ }^{6}$.

Com isso, ao analisar os dados em conjunto, foi gerada uma matriz temática a partir das questões do instrumento das entrevistas individuais e dos temas abordados nos grupos de convergência, resultando na categoria intitulada Convivência com o tratamento - pontos dificultadores na realização da CAPD no domicílio.

\section{Resultados e Discussão}

\section{Convivência com o tratamento: pontos dificul- tadores na realização da DPAC no domicílio}

Com relação às dificuldades, o fato de não poder trabalhar fora de casa preocupa muito os clientes, principalmente aqueles que sempre foram os responsáveis diretos pelo sustento de suas famílias.

E o que mais me incomoda é que não posso mais trabalhar, porque essa doença me cansa muito, e também se estiver atendendo alguém, não vou poder parar para fazer o tratamento, então pode atrasar [...] com isso eu não posso mais trabalhar. (Cravo)

Inicialmente, a incapacidade física dos clientes para o trabalho causa uma sensação de limitação, especialmente naqueles que eram os provedores da família, e até mesmo nos que apenas ajudavam nas despesas domésticas. Todavia, com o passar do tempo, eles percebem que precisam contornar esta situação em benefício próprio e no de seus familiares, não só por questões financeiras, mas por outras, relacionadas ao desenvolvimento de uma atividade, que faça com que se sintam dispostos, úteis, tendo a percepção da possibilidade de dar um novo sentido às suas vidas ${ }^{4}$. 
Outro fato mencionado deixou claro que, além do início da realização do tratamento, o acondicionamento dos materiais em casa também era motivo de preocupação para os clientes que, em sua maioria, residiam em domicílios pequenos e, geralmente, acompanhados por familiares. Sendo assim, em alguns momentos, a quantidade de materiais atrapalhava o convívio e o conforto de todos.

Eu morava em um apartamento pequenininho, então quando eu vi aquele material todo chegando eu pensei: meu Deus! Como eu vou botar isso tudo dentro da minha casa? E a minha família? Mas logo depois eu tratei de organizar um cantinho, na minha varanda, por que eu não queria que nada me atrapalhasse, então dei logo um jeito. (Gardênia)

Constata-se, assim, que as situações de dificuldades são contornadas com mais facilidade por dois motivos: o primeiro, quando o cliente procura organizar, por si só, os elementos necessários ao seu tratamento, adaptando, por exemplo, os locais para acondicionamento dos materiais, conforme os ensinamentos do processo educativo junto à sua realidade, podendo colocar em prática os conhecimentos provenientes de suas experiências de vida. $\mathrm{O}$ segundo expressa a oportunidade proporcionada pelo método da PCA, do compartilhamento de experiências e vivências entre os clientes, no momento da realização dos grupos de convergência ${ }^{6}$.

$\mathrm{O}$ processo de enfrentamento da doença renal crônica pelo cliente envolve a compreensão do seu significado e reflexos na rotina diária, nas relações e na própria concepção de vida. A maneira como reagirão frente aos agravos de saúde e os mecanismos que utilizarão para enfrentá-los estão relacionados às suas crenças, aos seus valores e ao apoio recebido dos profissionais de saúde e de sua rede social, geralmente integrada por familiares e amigos ${ }^{8}$.

Uma questão relevante para o cliente, e que merece especial atenção da equipe de enfermagem, é o cateter para diálise peritoneal, que é denominado de acordo com o tipo. Na maioria dos casos, o de Tenckhoff é o mais utilizado, por ser considerado padrão e permitir uma fácil infusão de líquidos, embora seja motivo de incômodo por parte de alguns clientes, principalmente no que se refere à sua permanência no corpo, causando problemas de autoimagem que podem prejudicar sua autoestima9 ${ }^{9}$ Porém, é importante ficar claro que após a fase inicial da doença, quando mais adaptado àquele cateter e confiante no seu tratamento, o cliente muda sua percepção negativa, passando a percebê-lo como uma parte de si, necessária ao desenvolvimento do tratamento ${ }^{10}$.

[...] não me conformava (com o cateter) olhava para ele e me dava vontade de arrancar e jogar fora; tudo que eu usava marcava na barriga, estava me sentindo feia [...] com o passar do tempo, o tratamento foi caminhando e comecei a me acostumar, depois não o via mais como um problema e, sim, como uma necessidade, então, ele passou a ser meu amiguinho! (Orquídea)

Cuidar do cateter pode ser considerada uma forma de autocuidado realizado pelos clientes, com base no sistema de apoio/educação. Nesse caso, eles são orientados que podem e devem executar medidas de autocuidado terapêutico, como a escolha do meio, do material e da forma adequada de realizar o procedimento, refletindo-se o autocuidado para além da técnica ao se configurar como uma atitude de enfrentamento ${ }^{4}$.

A propósito das interferências no cotidiano dos clientes, em alguns momentos, a DPAC causa limitações, principalmente em relação à vida social, fazendo com que se sintam preocupados com as restrições ao convívio com outras pessoas e à participação em eventos sociais.

Tem hora que dá vontade de falar: Eu não vou fazer não! É muito chato, toda hora tem que estar fazendo, porque tem dia que parece que passa rápido, faz uma troca agora e, logo depois, tem que fazer a outra [...] de vez em quando cansa porque está toda minha família reunida com meus vizinhos, batendo papo na varanda, e eu tenho que sair para fazer a troca [...] mas é só quando está todo mundo junto, porque atrapalha meu convívio social. (Gardênia)

A participação em alguma atividade social ou evento, que os clientes julguem ser mais importante do que o seu tratamento, causa preocupação, pois eles poderão desenvolver a técnica da DPAC de forma rápida e inadequada, favorecendo a ocorrência de falhas.

$\mathrm{O}$ autocuidado inclui ações deliberadas e sistemáticas, executadas para satisfazer exigências de saúde identificadas e próprias. No momento em que a realização do tratamento é prejudicada por questões relacionadas às escolhas dos clientes, fica claro que não estão sendo executadas as ações de forma adequada e, por consequência, as exigências de saúde não estão sendo atendidas ${ }^{4}$.

O tratamento me incomoda só na hora de parar para fazer [...] você está fazendo alguma coisa e tem que largar tudo para lá e ir, lá, fazer... (Hortência)

A ocorrência de situações que possam causar risco à saúde e ao tratamento é constatada em maior escala junto àqueles que possuem mais tempo de DPAC. Essa clientela, por julgar que dispõe de mais conhecimento do que aquele que está iniciando, e também pelas vivências que possui, está sujeita a cometer imprudências ao desafiarem o tratamento. É quando as possibilidades de intercorrências aumentam, trazendo o risco da instalação da peritonite, por possíveis contaminações em algumas ou várias das etapas da técnica cumprida incorretamente. 
Nesse sentido, é relevante a troca ou o compartilhamento de experiências e conhecimentos entre a enfermeira e o cliente, e dos clientes entre si, visando alertar para que o cuidado seja realizado da melhor forma com o intuito de minimizar esses conflitos da prática no domicílio ${ }^{4,5}$.

O respeito à autonomia e à dignidade de cada um é um imperativo ético e não um favor que se pode ou não conceder aos outros. A troca de saberes deve ser acompanhada de um processo educativo horizontal, com manutenção do diálogo e das orientações, pela via democrática. É preciso a participação ativa dos clientes, respeitando suas singularidades e vivências, com vistas à realização de práticas benéficas de autocuidado 5 .

Com isso, fica evidenciado que os cuidados técnicos e as ações educativas desenvolvidos pela equipe de enfermagem estão diretamente ligados ao exercício da cidadania para a obtenção da autonomia ${ }^{5}$. Porém, para que esse processo educacional aconteça, é necessário que o cliente busque sempre conhecer o seu corpo, pois quanto maior for o seu conhecimento acerca do processo da doença e do tratamento, maior será o seu envolvimento no autocuidado, confirmando o alcance da sua autonomia ${ }^{4}$.

Ainda, no que se refere às possíveis dificuldades do tratamento no domicílio, certos sujeitos da pesquisa relataram que possuem, como agentes dificultadores, alguns membros de suas famílias. Isto ocorre porque as limitações impostas pela doença crônica afetam também a família, que precisa se adaptar às necessidades de quem ficou doente ${ }^{4}$. Há uma quebra do equilíbrio familiar diante do novo evento e as adaptações que esta família deverá realizar dependerão dos recursos disponíveis, de como a doença começou e do significado que for atribuído a esse acontecimento ${ }^{11}$.

A minha família, por parte de irmão e parentes, não me procura, é muito difícil, e [...] ajudar, eles não ajudam. Se depender da minha família, por parte de parente, estou ferrada, ninguém me ajuda, assim, em nada [...] só o meu marido me ajuda; a minha filha que mora na minha casa, essa não quer saber de nada. (Lírio)

Depreende-se que os familiares desses clientes não os ajudam apenas por simples recusa, a fim de não assumirem qualquer tipo de responsabilidade relacionada com quem foi acometido pela doença renal crônica. Nesses casos, a preocupação da equipe de enfermagem é não deixar que esta situação leve o cliente a desenvolver sentimentos de abandono, revolta e depressão, por não conseguir entender e aceitar a ocorrência desses fatos, prestando-lhe apoio e suporte ${ }^{12}$.

Esse suporte da equipe de enfermagem visa também à implementação de estratégias para estimular a aceitação da doença e do tratamento por parte da família, desde o início do processo, o que poderá contribuir para a segurança e a autoestima do cliente que realiza a diálise em casa. Tal aceitação decorre de um processo que pode ser tanto lento quanto de forma abrupta e inesperada, que se institui desde o diagnóstico da patologia, cujas evolução e terapêutica geram o quadro de dependência de cuidados no domicílio. Relaciona-se também com o vínculo afetivo ou com a responsabilidade social em função do grau de parentesco. A vinculação ao familiar acometido pela doença interfere na trajetória de vida, exigindo mudanças, adaptações e consolidação de conhecimentos e atitudes para lidar com a nova realidade que se impõe ${ }^{13}$.

Dessa forma, é pertinente citar alguns fatores que as famílias precisarão superar em relação ao cliente: redução da ansiedade, fornecimento de informações e apoio, proximidade ao cliente e sentimento de solidariedade, que só serão possíveis se cada familiar vivenciar o processo de enfrentamento junto com o cliente ${ }^{14,15}$.

\section{Conclusão}

O estudo confirmou a necessidade de repensar a lógica de construção dos saberes dos clientes portadores de insuficiência renal crônica em tratamento com a DPAC, procurando identificar a pedagogia que orienta este tratamento quando realizado no domicílio.

A questão familiar que enfocou as dificuldades de realização da diálise evidenciou um contraponto. Os clientes sentem maior segurança, confiança e estabilidade emocional para realizar o autocuidado no domicílio quando a família é participativa em relação ao processo de tratamento. Quando ocorre o contrário, independente do motivo causador dessa ausência de cooperação, sentem-se sozinhos, desestimulados e até desamparados, sem entender os motivos dessa falta de participação familiar.

processo educativo deve levar em consideração a realidade domiciliar de cada cliente, intermediando sua realidade social à forma preconizada pelo setor de DPAC para o armazenamento desses materiais, contribuindo para o planejamento e a organização do seu acondicionamento e uso, a fim de evitar que sejam eventualmente danificados.

Cabe lembrar a importância de os clientes receberem orientações que lhes permitam ter uma visão crítica e reflexiva a respeito do autocuidado. Para tanto, é necessário a revisão do processo educativo atual, realizado pela equipe de enfermagem, a fim de que os saberes transmitidos sejam associados à realidade social dessa clientela, para atingir a melhor maneira de desenvolver o tratamento preconizado nos respectivos contextos domiciliares.

\section{REFERÊNCIAS}

1.Brunno LSX, Santos I, Almeida RF, Clos AC, Santos MTS. Características individuais e clínicas de clientes com doença renal crônica em terapia renal substitutiva. Rev enferm UERJ. 2014; 22:314-20. 
2.Fernandes MICD, Medeiros ABA, Macedo BM, Vitorino ABF, Lopes MVOL, Lira ALBC. Prevalência do diagnóstico de enfermagem volume de líquidos excessivo em pacientes submetidos à hemodiálise. Rev esc enferm USP. 2014; 48:446-53.

3.Barreto MS, Marcon SS. Doença renal crônica: vivências e expectativas do cuidador. Rev enferm UERJ. 2012; 20:374-9.

4.Orem DE. Nursing: concepts of practice. $3^{\text {rd }}$ ed. New York: McGraw-Hill Book Co.; 1995.

5.Freire P. Pedagogia da autonomia - saberes necessários à prática educativa. São Paulo: Paz e Terra; 2011.

6.Trentini M, Paim L. Pesquisa convergente-assistencial: um desenho que une o fazer e o pensar na prática assistencial em saúde-enfermagem. Florianópolis (SC): Insular; 2004. 7.Bardin L. Análise de conteúdo. 3a ed. Lisboa (Pt): Edições 70; 2012.

8.Pacheco GS, Santos I, Bregman R. Características de clientes com doença renal crônica: evidências para o ensino do autocuidado. Rev enferm UERJ. 2006; 14:434-9. 9.Santos AAA, Vasconcelos HVG, Betônico GN. Avaliação dos potenciais erros na realização da diálise peritoneal automatizada. Colloquium Vitae. 2011; 3(Esp):3-14.
10.Carneiro RL. O conhecimento do cliente em prétransplante renal sobre o autocuidado: desafios para a enfermagem no desenvolvimento da consciência crítica. [dissertação de mestrado]. Rio de Janeiro : Universidade Federal do Rio de Janeiro; 2006.

11.Freitas KS, Menezes IG, Mussi FC. Conforto na perspectiva de familiares de pessoas internadas em Unidade de Terapia Intensiva. Texto contexto enferm. 2012;21: 896-904.

12.Rosa LM, Silva AMF, Pereima RSMR, Santos SMA, Meirelles BHS. Família, cultura e práticas de saúde: um estudo bibliométrico. Rev enferm UERJ. 2009; 17:516-20.

13.Costa SRD, Castro EAB. Autocuidado do cuidador familiar de adultos ou idosos dependentes após a alta hospitalar. Rev Bras Enferm. 2014; 67 (6):979-86.

14.Mota MS, Gomes GC, Petuco VM, Heck RM, Barros EJL, Gomes VLO. Facilitadores do processo de transição para o autocuidado da pessoa com estoma: subsídios para enfermagem. Rev esc enferm USP. 2015; 49:82-8.

15.Bedina LF, Busanellob J, Sehnemc GD, Silva FM, Poll MA. Estratégias de promoção da autoestima, autonomia e autocuidado das pessoas com feridas crônicas. Rev Gaúcha Enferm. 2014; 35:61-7. 